\title{
The coupled heating optimization of hybrid GCHP system with heat compensation unit
}

\author{
Tian You, Xianting Li*, Wei Wu, Wenxing Shi, Baolong Wang
}

\begin{abstract}
The coupled HCUT-GCHP system (integrating the GCHP with the efficient heat compensation unit (HCUT)) can operate in heat compensation mode and coupled heating mode to effectively eliminate the soil thermal imbalance and increase the heating supply at peak heating load. The coupled heating strategy directly influences the soil heat extraction not only at the peak. load but also during the whole year. The system model is built in TRNSYS to investigate the optimal strategies of the coupled HCUT-GCHP systems with different boreholes. Results show that the systems with $80 \%$ and $100 \%$ boreholes can keep soil thermal balance well at different starting temperatures of coupled heating mode. Taking the system with 60\% boreholes as an example, when the starting temperature of coupled heating mode increases from $0^{\circ} \mathrm{C}$ to $9^{\circ} \mathrm{C}$, the power consumption for heating increases by $7.32 \mathrm{MWh} /{ }^{\circ} \mathrm{C}$, while the power consumption for heat compensation decreases by $9.40 \mathrm{MWh} /{ }^{\circ} \mathrm{C}$. For the systems with $100 \%, 80 \%$, 60\% and $40 \%$ boreholes, the optimal starting temperatures of coupled heating modes are respectively $9^{\circ} \mathrm{C}, 9^{\circ} \mathrm{C}, 6^{\circ} \mathrm{C}$ and $3^{\circ} \mathrm{C}$ and their annual system $\mathrm{COPs}$ are respectively 2.66, 2.64, 2.63 and 2.48 under the optimal strategies.
\end{abstract}

\section{INTRODUCTION}

Annual soil thermal imbalance (Wu et al. 2013, Zhu et al. 2014, You et al. 2016a), heating deficiency at peak heating load (Rad et al. 2013, Gehlin and Spitler 2014) and large borehole cost (Garber et al. 2013) are three important factors influencing the GCHP performance and hamper its application in heating dominant buildings. To deal with these problems, the hybrid GCHP systems integrated with boiler, solar collector are common in the research and the practical projects. However, the low energy efficiency of boiler (Ni et al. 2016) makes the system's efficiency decrease and the expensive initial cost of solar collector (Bi et al. 2004, Si 2014) make the system's payback time increase respectively.

Heat compensation unit with thermosyphon (HCUT) is a compact unit combining air source thermosyphon and heat pump together (You et al. 2015), of which the principle is shown in Figure 1. Compared with the conventional air source heat pump, only the three-way valve and solenoid valve are added in HCUT. When the temperature difference between air and water is large enough to driven thermosyphon, the heat from air can be naturally transferred to the water with a very high COP (12.46 under the rated condition). The refrigerant flows along the solid line in Figure 1(a). When the temperature difference is not enough, the compressor works to increase the heat capacity, as the solid line in Figure 1(b). Consequently, HCUT can fully use the heat in the air at different temperatures.

The HCUT-GCHP system (integrating the GCHP with the HCUT) is proposed in the authors' previous work Xianting Li (xtingli@tsinghua.edu.cn) is a professor of building science and Tian You is a PhD student at Tsinghua University. 
(You et al. 2014, Li et al. 2011). It can eliminate the soil thermal imbalance efficiently and economically. In this system, HCUT can compensate heat into soil efficiently as air source thermosyphon or heat pump in heat compensation mode during non-heating season. Recently, the authors proposed the coupled heating operation of HCUT and GCHP during the heating season to solve the heating deficiency and reduce the number of boreholes (You et al. 2016b). The operation of the coupled heating mode not only influences the accumulated soil heat extraction related to annual soil thermal balance, but also influences the peak soil heat extraction related to the heat supply at peak heating load and the number of boreholes. So, it is essential to optimize the coupled heating strategy of HCUT.

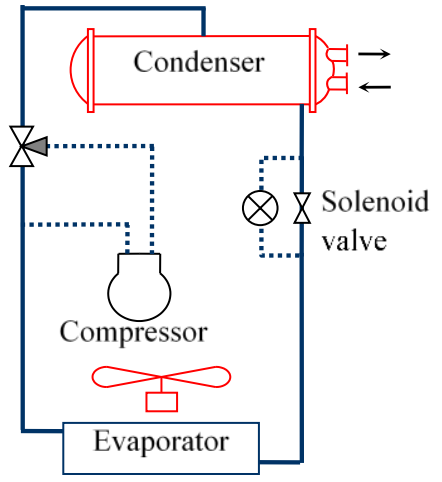

(a) Air source thermosyphon

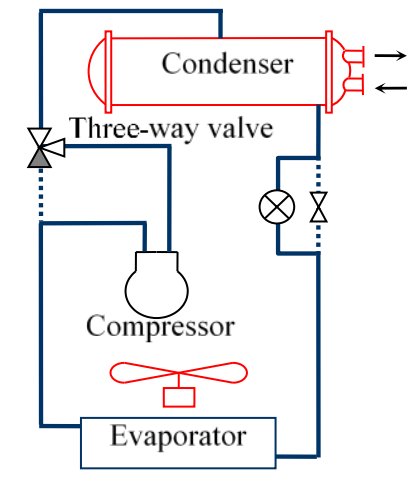

(b) Air source heat pump Figure 1 Principle of HCUT

In this paper, for the coupled HCUT-GCHP system with different reduced boreholes, the coupled heating strategies of HCUT are optimized respectively to improve the systems' performance and reduce the systems' cost. The coupled HCUT-GCHP system model is built in TRNSYS to simulate the system applied in a Harbin hotel. The system performance on keeping soil thermal balance, the detailed system energy consumptions under different strategies and the system heating COPs during different periods are investigated. At last, the optimal coupled heating strategy for systems with different boreholes is found out.

\section{SYSTEM PRINCIPLE AND OPERATION STRATEGY}

\subsection{System principle}

The system principle of the coupled HCUT-GCHP proposed previously is illustrated in Figure 2. HCUT is an auxiliary unit in the hybrid GCHP, which has a compact structure by sharing the evaporator and condenser of airsource thermosyphon and air-source heat pump and can easily shift between them by a self-control valve. Since HCUT has high performance when outdoor air temperature is high, it can compensate heat from air into soil efficiently in non-heating season to keep annual soil thermal balance of GCHP in heating dominant buildings, which is heat compensation mode in Figure 2(a).

Besides, reducing the soil heat extraction is another way to keep soil thermal balance annually and reduce the number of boreholes. HCUT can operate as air source heat pump during heating period to extract heat from air to reduce the soil heat extraction, which is coupled heating mode in Figure 2(b). In the coupled heating mode, borehole outlet water flows into HCUT and is reheated by the heat from air, then flows into GCHP unit. The coupled heating of HCUT can improve the heating COP and capacity of GCHP unit. However, due to the additional power consumption of HCUT, the system heating COP is not always higher than the normal GCHP heating. But, the reduced soil heat compensation benefits to the whole system COP. Besides, number of boreholes can be reduced due to the heat extraction from air. 


\subsection{Operation strategy}

The coupled heating of HCUT not only benefits the annual soil thermal balance but also reduces the needed number of boreholes. As a consequence, the operation strategy of HCUT in coupled heating mode should be optimized to improve the system efficiency as well as the system cost.

Because the evaporator inlet temperature of GCHP $\left(\mathrm{T}_{\mathrm{ei}}\right)$ directly influences the heating COP and capacity of GCHP, it's good for the improvement of heating performance by keeping $\mathrm{T}_{\mathrm{ei}}$ high. Thus, the borehole outlet temperature should be elevated before entering GCHP by the HCUT in coupled heating mode. If the acceptable lowest $\mathrm{T}_{\mathrm{ei}}$ is set as $\mathrm{T}_{\mathrm{e} i \mathrm{i}}$, it means $\mathrm{T}_{\mathrm{e} i 0}$ is also the starting temperature of HCUT in coupled heating mode. When the borehole outlet temperature is above $\mathrm{T}_{\mathrm{e} i}$ in winter, HCUT doesn't operate and the borehole outlet fluid flows into GCHP evaporator directly. When the borehole outlet temperature is lower than $\mathrm{T}_{\mathrm{e} i 0}$ in winter, HCUT operates in coupled heating mode. So, when the $\mathrm{T}_{\mathrm{e} i 0}$ increases, the operating time of coupled heating mode increases correspondingly and less heat is extracted from the soil.

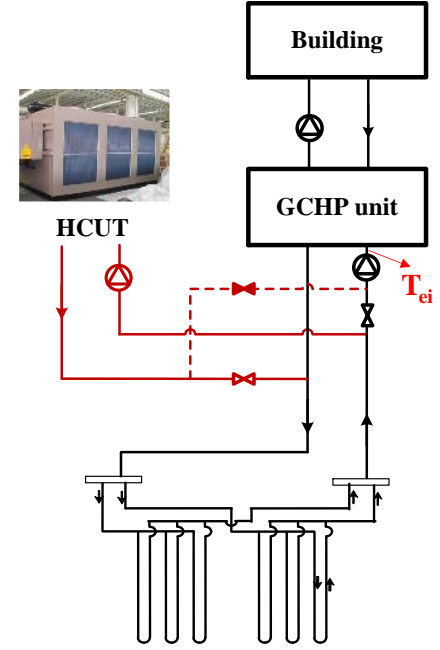

(a) Heat compensation mode Figure 2 HCUT's operating modes of the coupled HCUTGCHP system

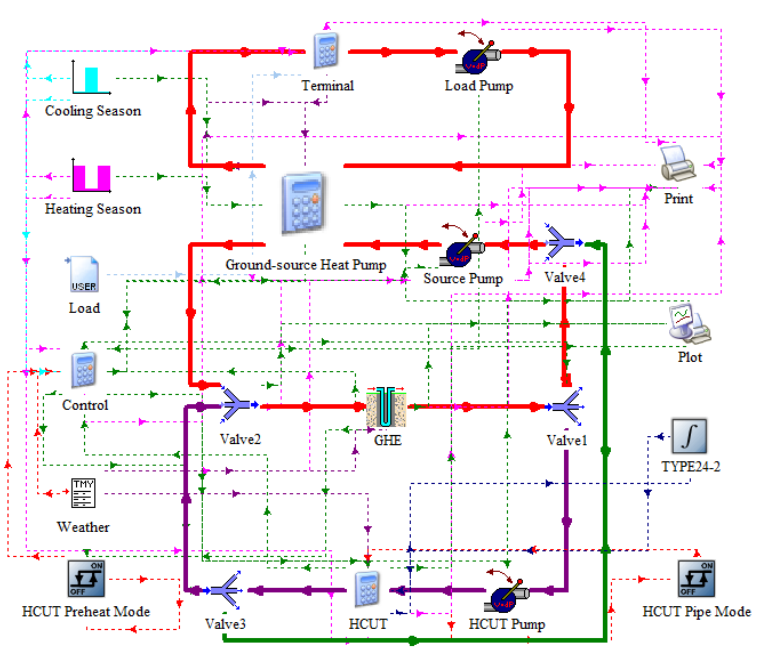

Figure 3 HCUT-GCHP system model based on TRNSYS

\section{METHODOLOGY}

\subsection{System model}

The coupled HCUT-GCHP system applied in a hotel building in Harbin is simulated in this paper. The maximum heating and cooling loads are respectively $636 \mathrm{~kW}$ and $366 \mathrm{~kW}$. The accumulated heating load is $1220 \mathrm{MWh}$, far larger than the accumulated cooling load (181MWh).

The system model (You et al. 2014) is built in TRNSYS software (Hellström et al. 1996, Klein et al., 2004.) to simulate the hourly system performance in a long term, as shown in Figure 3. The capacities of main components in system are shown in Table 1. Due to the coupled heating, the system can operate well with $40 \% \sim 100 \%$ boreholes. But, with the number of boreholes reducing from 140 to 56, the capacity of HCUT increases from 250kW to 500kW to keep the heat supply enough at peak heating load. 
Table 1. Capacities of main components in HCUT-GCHP systems

\begin{tabular}{lcccc}
\hline Items & $\mathbf{1 0 0} \%$ boreholes & $\mathbf{8 0} \%$ boreholes & $\mathbf{6 0 \%}$ boreholes & 40\% boreholes \\
\hline \hline Number of boreholes & 140 & 112 & 84 & 56 \\
Rated heat capacity of HCUT $(\mathrm{kW})$ & 250 & 260 & 350 & 500 \\
Rated heat capacity of GCHP unit $(\mathrm{kW})$ & 1223 & 1223 & 1223 & 1223 \\
\hline
\end{tabular}

\subsection{Case studies}

For the coupled HCUT-GCHP systems with different reduced numbers of boreholes, the optimized coupled heating strategies are different to keep the systems at good performance. Several cases with different strategies are studied for systems with different boreholes, as shown in Table 2 . The starting temperatures $\left(\mathrm{T}_{\mathrm{e} i 0}\right)$ of the coupled heating mode are respectively $0^{\circ} \mathrm{C}, 3^{\circ} \mathrm{C}, 6^{\circ} \mathrm{C}, 9^{\circ} \mathrm{C}, 12^{\circ} \mathrm{C}, 15^{\circ} \mathrm{C}$. This is because if $\mathrm{T}_{\mathrm{e} i 0}$ is too low, the coupled mode only operates for a short period and the reduction of soil heat extraction is small, and if $\mathrm{T}_{\mathrm{ei} 0}$ is high enough, independent GCHP is efficient enough and there is no need to operate coupled heating. For systems with $40 \%$ and $60 \%$ boreholes, $\mathrm{T}_{\mathrm{ei}}$ is less than $9^{\circ} \mathrm{C}$ to avoid the serious soil heat accumulation, which is illustrated in Figure 4 .

Table 2. Case studies of systems with different boreholes and operating strategies

\begin{tabular}{|c|c|c|c|c|c|c|c|}
\hline & & \multicolumn{6}{|c|}{ Starting temperatures of coupled heating mode(Tei0) } \\
\hline & & $0^{\circ} \mathrm{C}$ & $3^{\circ} \mathrm{C}$ & $6^{\circ} \mathrm{C}$ & $9^{\circ} \mathrm{C}$ & $12^{\circ} \mathrm{C}$ & $15^{\circ} \mathrm{C}$ \\
\hline \multirow{3}{*}{$\begin{array}{c}\text { Numbers of } \\
\text { boreholes }\end{array}$} & $100 \%$ boreholes & $\sqrt{ }$ & $\sqrt{ }$ & $\sqrt{ }$ & $\sqrt{ }$ & $\sqrt{ }$ & $\sqrt{ }$ \\
\hline & $60 \%$ boreholes & $\sqrt{ }$ & $\sqrt{ }$ & $\sqrt{ }$ & $\sqrt{ }$ & $x$ & $x$ \\
\hline & $40 \%$ boreholes & $\sqrt{ }$ & $\sqrt{ }$ & $\sqrt{ }$ & $\sqrt{ }$ & $x$ & $x$ \\
\hline
\end{tabular}

\section{RESULTS}

To investigate the optimal strategy of coupled HCUT-GCHP with different boreholes, system performance is analyzed in three aspects. Firstly, the system abilities of keeping the annual soil thermal balance and reducing soil heat extraction are illustrated, which are the basic purposes of hybrid HCUT-GCHP. Secondly, taking the system with 60\% boreholes as an example, detailed energy consumption and efficiency under different strategy are compared. Thirdly, the different optimal strategies for systems with different boreholes are found out through comparisons.

\subsection{Soil thermal balance}

The soil thermal imbalance ratios of different systems with different boreholes and different coupled heating strategies are shown in Figure 4. With the increase of soil heat compensation and the reduce of soil heat extraction, the soil thermal imbalance can be effectively eliminated by most coupled HCUT-GCHP, such as systems with $80 \%$ or $100 \%$ boreholes under different strategies. For the system with $40 \%$ and $60 \%$ boreholes, the capacity of HCUT should be large to satisfy the heating demand at peaking heating load and the soil heat extraction is greatly reduced. Especially when the starting temperature of coupled heating mode increases, the soil heat injection for cooling becomes even larger than the soil heat extraction for heating. The soil thermal imbalance ratio turn to be far higher than $10 \%$, which means the heat is accumulated in soil, going to the opposite thermal imbalance unfavorable to cooling performance and system energy saving. For the system with $40 \%$ boreholes, if the starting temperature of coupled heating mode is higher than $6^{\circ} \mathrm{C}$ or $9^{\circ} \mathrm{C}$, the soil thermal imbalance ratio is about $42 \%$ and $74 \%$. 


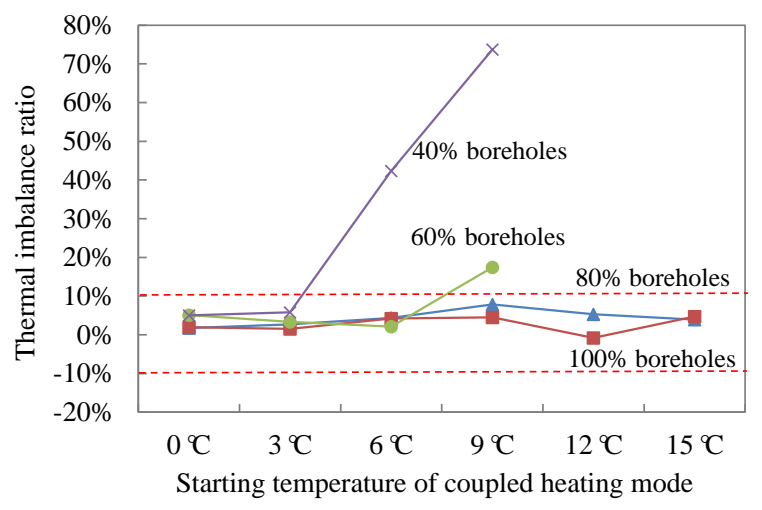

Figure 4 Thermal imbalance ratio of different coupled HCUT-GCHP systems

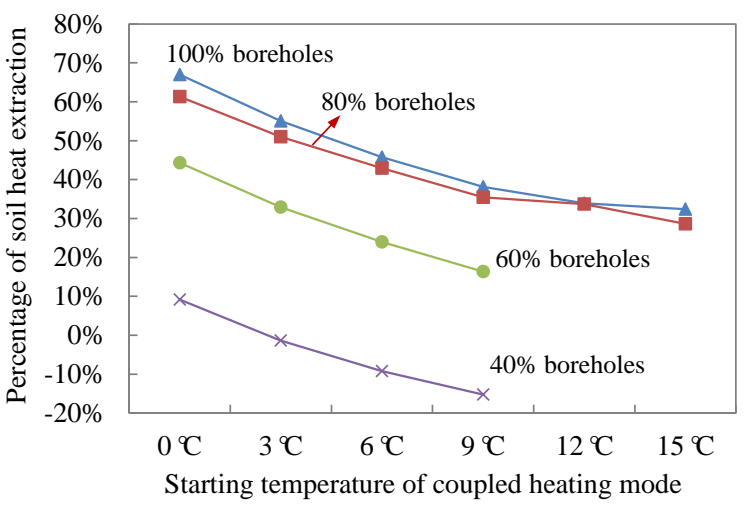

Figure 5 Percentages of soil heat extraction of different coupled HCUT-GCHP systems

The coupled HCUT-GCHP system can extract heat from air and soil. The percentage of soil heat extraction accounted for the total value from air and soil is demonstrated in Figure 5. When the number of boreholes is reduced or the starting temperature of the coupled heating mode increases, the heat extraction from soil decreases. Taking the system with $60 \%$ boreholes as an example, the percentage of soil heat extraction decreases from $44 \%$ to $16 \%$, when the starting temperature increases from $0^{\circ} \mathrm{C}$ to $9^{\circ} \mathrm{C}$. For the systems with $40 \%$ boreholes, the annual soil heat extraction becomes negative, when the starting temperature is higher than $6^{\circ} \mathrm{C}$. It means the HCUT reheats the fluid to a too high temperature, the evaporator outlet fluid temperature is higher than the soil. The borehole is useless under this circumstance, so the strategy is not proper here.

\subsection{Efficiencies under different strategies}

Taking the system with $60 \%$ boreholes as an example, power consumption, hourly system heating COP and average system COP during different period are analyzed to discover the influence of different coupled heating strategies.

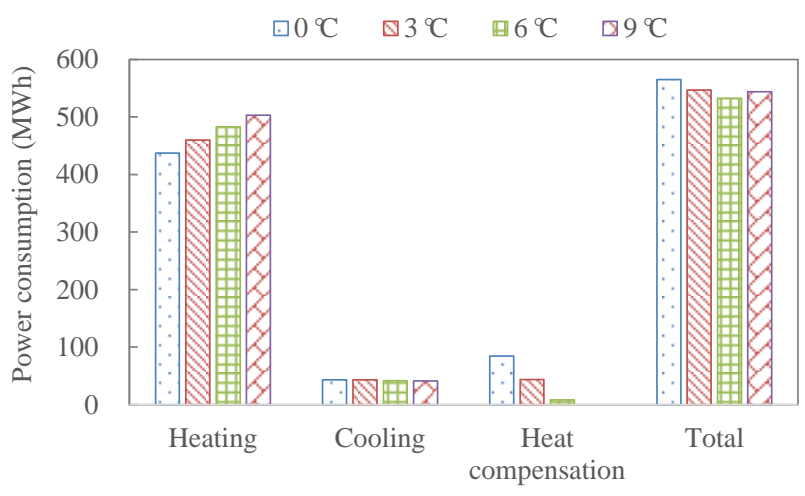

Figure 6 Power consumptions of systems with different strategies

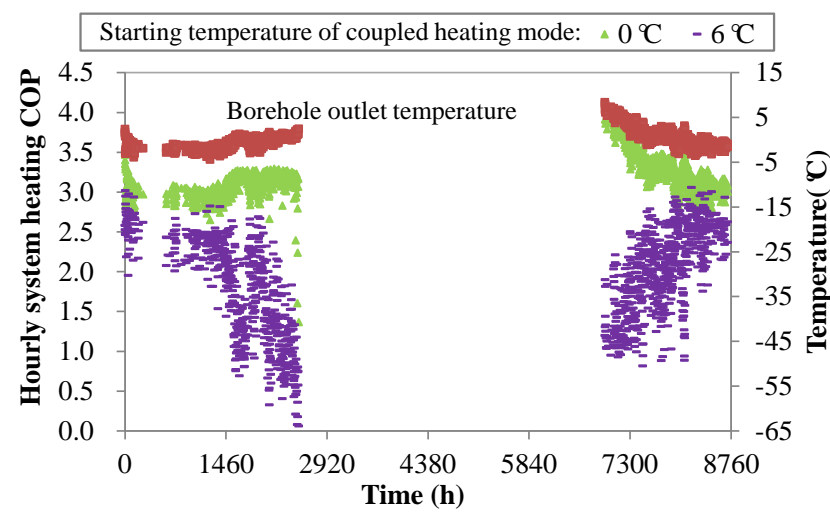

Figure 7 Hourly COP and temperature of systems with different strategies

Power consumptions for heating, cooling and heat compensation under different starting temperatures of coupled heating mode are shown in Figure 6 . When the $\mathrm{T}_{\text {ei } 0}$ increases from $0^{\circ} \mathrm{C}$ to $9^{\circ} \mathrm{C}$, the power consumption for heating increases from $437 \mathrm{MWh}$ to $503 \mathrm{MWh}$, while power consumption for heat compensation decreases from $85 \mathrm{MWh}$ to $0 \mathrm{MWh}$. This is because when the borehole outlet temperature becomes high, the coupled heating system's 
COP is always lower than that of normal heating system at the same time, which is shown in Figure 7. But, since less heat is extracted from the soil in coupled heating mode, less heat is needed for compensation. When $\mathrm{T}_{\text {ei } 0}$ increases from $0^{\circ} \mathrm{C}$ to $6^{\circ} \mathrm{C}$, the dropping power consumption for heat compensation makes the total system power consumption drop from $565 \mathrm{MWh}$ to $533 \mathrm{MWh}$. However, if $\mathrm{T}_{\mathrm{e} i 0}$ increases from $6^{\circ} \mathrm{C}$ to $9^{\circ} \mathrm{C}$, the total power consumption increases from $533 \mathrm{MWh}$ to $544 \mathrm{MWh}$. This is because the slightly reduced power consumption for heat compensation is less than the seriously increased power consumption for heating.

The hourly system heating COP and borehole outlet temperature of system with $60 \%$ boreholes under $0^{\circ} \mathrm{C}$ and $6^{\circ} \mathrm{C}$ starting temperatures are demonstrated in Figure 7. From the above mentioned system principle, the system with $6^{\circ} \mathrm{C}$ starting temperature has longer coupled heating period than that with $0^{\circ} \mathrm{C}$ starting temperature. For the coupled heating period during which both systems operated, their average system COPs are nearly the same, which is shown in Figure 8. However, for the period that system with $6^{\circ} \mathrm{C}$ starting temperature operates in coupled heating mode and system with $0^{\circ} \mathrm{C}$ starting temperature operates in normal heating mode, the system COPs are quite different as shown in Figure 7.

When the $\mathrm{T}_{\text {ei }}$ is $6^{\circ} \mathrm{C}$, due to the power consumption of both HCUT and GCHP, the average system heating $\mathrm{COP}$ in coupled heating mode is 1.93 . At the same time, for the system with $\mathrm{T}_{\text {ei } 0}$ of $0{ }^{\circ} \mathrm{C}$, since only GCHP works as normal heating, the average system heating COP is 3.21. Especially when the borehole outlet temperature is high, the system with $0^{\circ} \mathrm{C}$ starting temperature has much higher system heating $\mathrm{COP}$ than that with $6^{\circ} \mathrm{C}$ starting temperature.

Average system COPs during different period of coupled HCUT-GCHP under different strategies are shown in Figure 8. When the starting temperature of coupled heating mode increases from $0^{\circ} \mathrm{C}$ to $9^{\circ} \mathrm{C}$, the average system COPs during coupled heating period are nearly the same at $2.63 \sim 2.66$, while those during the total heating period decreases from 2.91 to 2.45 , because the increased coupled heating period of systems with higher $\mathrm{T}_{\text {ei } 0}$ has a lower COP, as shown in Figure 7. But the system with high $\mathrm{T}_{\mathrm{e} i 0}$ has a low power consumption for heat compensation, as shown in Figure 6. So, the average system COPs during the whole year is the highest (Figure 8), about 2.63 when the starting temperature of coupled heating mode is $6^{\circ} \mathrm{C}$ for system with $60 \%$ boreholes.

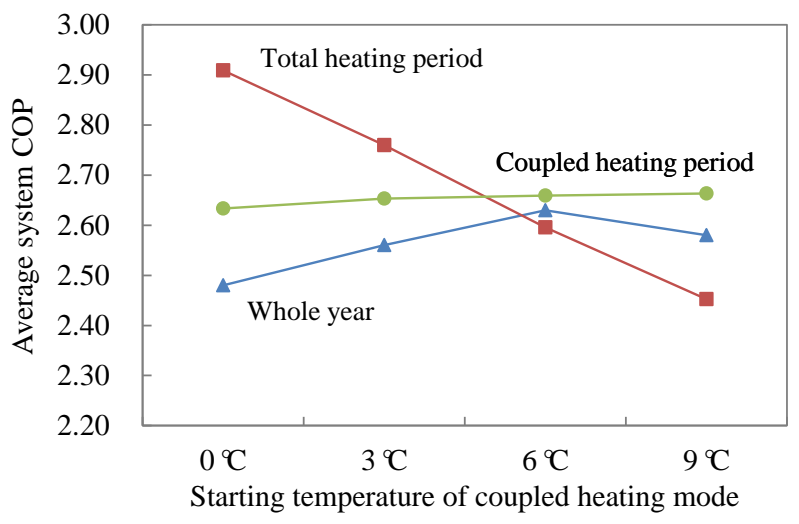

Figure 8 Average system COPs during different period under different strategies

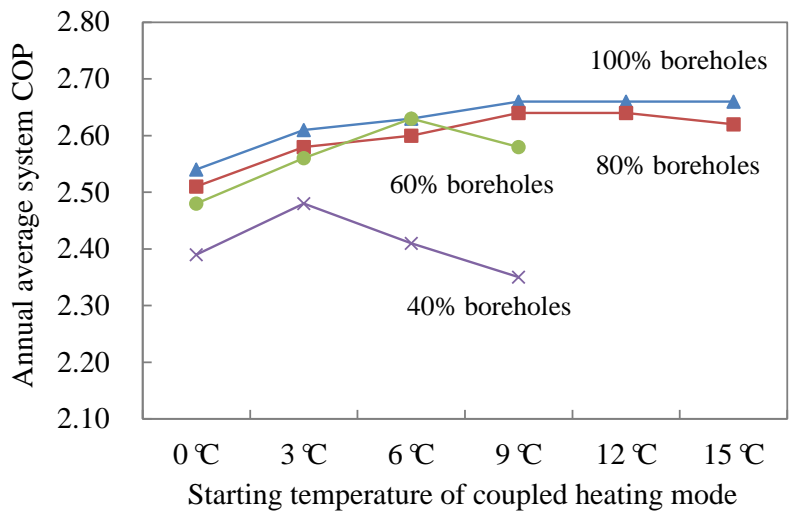

Figure 9 Annual average system COP variations of different systems under different strategies

\subsection{Optimal coupled heating strategies of different boreholes}

The annual average system COP variations of systems with different boreholes under different coupled heating strategies are shown in Figure 9. For the systems with different boreholes, the optimal starting temperature to achieve the highest annual average system COP is different, because the HCUT capacities and the needed heat compensations are different. The optimal starting temperatures of system with $100 \%, 80 \%, 60 \%$ and $40 \%$ boreholes are respectively $9^{\circ} \mathrm{C}, 9^{\circ} \mathrm{C}, 6^{\circ} \mathrm{C}$ and $3^{\circ} \mathrm{C}$. The highest annual average COPs of these systems are respectively 2.66, 2.64, 2.63, 2.48 
under the optimal strategies.

It should be noticed that, system with $60 \%$ boreholes has a slightly lower system COP, but the number of boreholes is much less, so the cost is less expensive than systems with other numbers of boreholes.

\section{CONCLUSION}

The performance of HCUT-GCHP in coupled heating mode directly influences the annual soil thermal balance and the system heat supply at peaking load. Therefore, the coupled heating strategy of HCUT-GCHP with different boreholes is optimized in this paper.

For the systems with $80 \%$ and $100 \%$ boreholes, they keep soil thermal balance well at different starting temperatures of coupled heating mode. However, for the systems with $40 \%$ and $60 \%$ boreholes, when the starting temperature should be kept at $0^{\circ} \mathrm{C} \sim 3^{\circ} \mathrm{C}$ and $0^{\circ} \mathrm{C} \sim 6^{\circ} \mathrm{C}$ respectively.

Taking the system with $60 \%$ boreholes as an example, when the starting temperature of coupled heating mode increases from $0^{\circ} \mathrm{C}$ to $9^{\circ} \mathrm{C}$, the power consumption for heating increases by $7.32 \mathrm{MWh} /{ }^{\circ} \mathrm{C}$, while the power consumption for heat compensation decreases by $9.40 \mathrm{MWh} /{ }^{\circ} \mathrm{C}$. Therefore, the system COP reaches highest at 2.63 when the starting temperature is $6^{\circ} \mathrm{C}$.

For the systems with $100 \%, 80 \%, 60 \%$ and $40 \%$ boreholes, the optimal starting temperatures of coupled heating mode are respectively $9^{\circ} \mathrm{C}, 9^{\circ} \mathrm{C}, 6^{\circ} \mathrm{C}$ and $3^{\circ} \mathrm{C}$ and their annual average system COPs are respectively $2.66,2.64$, 2.63 and 2.48 under the optimal strategies.

\section{ACKNOWLEDGMENTS}

The authors gratefully acknowledge the supports of Innovative Research Groups of the National Natural Science Foundation of China (Grant No.51521005) and National Natural Science Foundation of China (Grant No.51638010).

\section{NOMENCLATURE}

$T_{e i}=$ Evaporator inlet temperature of GCHP $\left({ }^{\circ} \mathrm{C}\right)$

$T_{e i 0}=$ Starting temperature of coupled heating mode $\left({ }^{\circ} \mathrm{C}\right)$

\section{REFERENCES}

Bi Y., Guo T., Zhang L., et al. 2004. Solar and ground source beat-pump system. Applied Energy, 78(2):231-245.

Garber D, Choudhary R, and Soga K. 2013. Risk based lifetime costs assessment of a ground source beat pump (GSHP) system design: Methodology and case study, Building and Environment, 60: 66-80.

Gehlin SEA and Spitler JD. 2014. Design of Residential Ground Source Heat Pump Systems for Heating Dominated Climates-Trade-Offs Between Ground Heat Exchanger Design and Supplementary Electric Resistance Heating, ASHRAE Transaction, 120(1): 1-8.

Hellström G, Mazzarella L, Pahud D, 1996, Duct Ground Storage Model-TRNSYS Version, Department of Mathematical Physics, University of Lund, Sweden.

Klein SA, Beckman WA, Mitchell JW, et al. 2004, TRNSYS 16-A Transient System Simulation Program User Manual, Solar Energy Laboratory, University of Wisconsin-Madison.

Ni L, Song W, Zeng FC, et al. 2011. Energy saving and economic analyses of design heating load ratio of ground source heat pump with gas boiler as auxiliary beat source, Electric Technology and Civil Engineering (ICETCE), 2011 International Conference on IEEE, 1197-1200.

Rad FM, Fung AS and Leong WH. 2013. Feasibility of combined solar thermal and ground source heat pump systems in cold climate, Canada, Energy and Buildings, 61: 224-232.

Si Q, M Okumiya, and Zhang X, 2014, Performance evaluation and optimization of a novel solar-ground source heat pump system, Energy and Buildings, 70: 237-245. 
Wu W, Wang BL, You T, et al. 2013. A potential solution for thermal imbalance of ground source heat pump systems in cold regions: Ground source absorption heat pump, Renewable Energy, 59: 39-48.

Li XT, Zhang Y, Yu LJ, et al. 2011, A ground-coupled heat pump system, China Patent ZL201120136605.5 (in Chinese).

You T, Wang BL, Wu W, et al. 2014. A new solution for underground thermal imbalance of ground-coupled heat pump systems in cold regions: heat compensation unit with thermosyphon, Applied Thermal Engineering, 64(1): 283-292.

You T, Wang BL, Wu W, et al. 2015. Performance analysis of hybrid ground-coupled heat pump system with multi-functions, Energy

Conversation Management 92: 47-59.

You T, Wu W, Shi WX, et al. 2016a. An overview of the problems and solutions of soil thermal imbalance of ground-coupled heat pumps in cold regions, Applied Energy, 177: 515-536.

You T, Shi WX, Wang BL, et al. 2016b. The performance analysis on the coupled heating of GCHP and the heat compensation unit, 20th National Academic Conference on HVACR, Haikou.

Zhu N, Hu PF, Xu LH, et al. 2014. Recent research and applications of ground source heat pump integrated with thermal energy storage systems: A review, Applied Thermal Engineering, 71(1): 142-151. 